\title{
Phenomenal Intentionality without Compromise
}

Katalin Farkas

Central European University, Budapest

Monist 91, no. 2 (2008): 273-293

\begin{abstract}
:
In recent years, several philosophers have defended the idea of phenomenal intentionality: the intrinsic directedness of certain conscious mental events which is inseparable from these events' phenomenal character. On this conception, phenomenology is usually conceived as narrow, that is, as supervening on the internal states of subjects, and hence phenomenal intentionality is a form of narrow intentionality. However, defenders of this idea usually maintain that there is another kind of, externalistic intentionality, which depends on factors external to the subject. We may ask whether this concession to content externalism is obligatory. In this paper, I shall argue that it isn't. I shall suggest that if one is convinced that narrow phenomenal intentionality is legitimate, there is nothing stopping one from claiming that all intentionality is narrow.
\end{abstract}

\section{1.}

Things could seem the same even if the world were a little different, or indeed very different. For example, if I had been transported to Twin Earth in my sleep, or had been deceived by an evil demon, or had been raised as a brain in a vat, things could seem exactly the way they seem now. And there could be other subjects, who are in different circumstances - on Twin Earth, in the vatworld, in the demon-world - to whom things seem exactly the same as they seem to me.

Let us say that when everything seems the same for two subjects, their phenomenal mental states or events are the same. (The subjects could be a pair of actual and counterfactual subjects, or two actual subjects, or the same subject at different times.) It has been questioned whether this notion is legitimate, by questioning whether we share any mental features with brains in vats, or whether the phenomenology of my water experiences is the same as the phenomenology of my Twin Earth Doppelgänger's twater experiences. However, for the purposes of this paper, I would like to put these views aside, and assume that this notion of phenomenal sameness is acceptable. will also assume - based on arguments given for example by Terence Horgan, George Graham, John Tienson and Brian Loar (Horgan and Tienson 2002, Horgan, Tienson and Graham 2004, Loar 2003) - that we can make sense of a notion of intentionality which is based on phenomenology alone. This is phenomenal intentionality, that is, the intrinsic directedness of certain conscious mental events which is inseparable from these events' phenomenal character. 
Given the assumption that internally identical subjects - for example embodied and brainin-a-vat counterparts, or Earth and Twin Earth Doppelgängers - have the same phenomenal states, they also share their phenomenal-intentional features. As defenders of phenomenal intentionality emphasise, phenomenal-intentional content is narrow content; that is, it supervenes on the subject's internal states (Horgan and Tienson 2002, 521, Loar 2003, 231, Kriegel forthcoming). Does this mean that externalist theories of content are mistaken? Not quite. According to Horgan, Tienson and Graham, the vindication of phenomenal intentionality does imply that strong externalist theories - that is, theories that ground all intentionality in connections to the external world - are mistaken (Horgan et al. 2004, 98). However, Horgan et al. also embrace a more moderate form of externalism, which holds that in addition to phenomenal intentionality, certain kinds of thoughts also have externalistic intentionality, with a corresponding wide content. Loar is also prepared to leave room for some form of externalism: he says that "the current externalist theory appears ... correct", since "externalists are right about reference and truth-conditions of thoughts" (Loar 2003, 231). $]^{2}$

We may ask whether this concession to content externalism is obligatory. In this paper, I shall argue that it isn't. I shall suggest that if one is convinced that narrow phenomenal intentionality is legitimate, there is nothing stopping one from claiming that all intentionality is narrow. $\square^{\beta}$

2.

According to Horgan, Tienson and Graham, certain types of singular thought - thoughts we would express by using demonstratives or proper names - are among those which have externalistic intentionality. These thoughts "involve singular thought-constituents whose referents (if any) are determined partly in virtue of certain external relations that obtain between you and those referents" (Horgan et al. 2004, 300). The thoughts that I would express by using the name 'Bill Clinton' refer to Bill Clinton, and the truth-conditions of these thoughts depend on how things are with Bill Clinton; whereas the phenomenally identical thoughts of my Doppelgänger on Twin Earth refer to Twin Clinton, and the truth-conditions of her thoughts depend on how things are with Twin Clinton. This is why Horgan et al. conclude that some sort of truth-conditions, and hence some sort of contents, are wide.

Another defender of phenomenal intentionality, however, apparently sees no need to incorporate externalistic intentionality in his theory. Uriah Kriegel considers the following problem: 
it may seem that when I think about my mother and my Doppelgänger thinks of hers, our conscious thoughts share their phenomenology, but not their content. And this would suggest - as it did to Horgan et al. - that narrow phenomenal intentionality is not sufficient to account for all the representational features of conscious thoughts. This conclusion can be avoided either by denying that my Twin and I share phenomenology, or by denying that my Twin and I do not share content. Kriegel opts for the latter, and explains:

There are two moves involved in this. The first is to construe the singular component of singular representations - what makes them about one specific concrete particular and not about a qualitatively indistinguishable particular - as a hidden indexical. The second is to adopt a broadly internalist treatment of indexicals, say in the style of Searle's (1983) token-reflexive account or the two-dimensional semantics of Jackson (1998) and Chalmers (2002, 2006)." (Kriegel forthcoming, ms 21-22)

I shall come back briefly to the question of whether all Twin Earth cases can be handled by treating expressions and thought-components as (hidden) indexicals, but let me for the moment focus on the second move. The token-reflexive account of indexicals suggested in Searle (1983) in fact has the result that my thought about my mother, and my Twin's corresponding thought about hers, have different intentional contents. According to Searle, thoughts that are directed at ourselves make essential reference to the owner of the thought. The content of my 'I'-thoughts essentially involves me, and the content my Twin's 'I'-thoughts essentially involves her. Hence they are different. Other indexicals are construed with reference to the relation things bear to me. This means that my thoughts about my mother essentially involve me as a component, and my Twin's thoughts about her mother essentially involve her (my Twin) as a component. Hence the two contents are different. (This is also the position adopted by Horgan et al.)

It is of course true that this theory is 'broadly internalist', in the sense that the content of our thoughts depend only on facts internal to the subject - including the fact of her being her. But it's not true that on this theory, internal duplicates - like my Twin and I - are in the same representational states. In fact, since on the type of account Searle offers, every singular reference to contingent particulars involves some relation to the self, I won't share any singular thought content with my Twin. Since similar treatment is given, e.g., to natural kind terms, I won't share any of those thoughts with my Twin either. That's a lot of mental difference between us. It may be asked 
whether a defender of phenomenal intentionality, who wants to adopt a Searlean account of indexicals, would want to reconsider the question of whether my Twin and I have the same phenomenal mental states. Given the difference between our mental lives, perhaps it would be better to say that the phenomenology of my conscious thoughts is different from hers, simply because they involve a different subject - that there is a primitive phenomenological difference between what it is like to be me and what it is like to be my Twin.

Another question is, however, whether one should adopt a Searlean account of indexicals. One apparent consequence of this account is that, strictly speaking, no-one else would be able to understand my singular thoughts, since these and only these thoughts essentially involve me. Searle is aware of this objection and attempts to give an answer, but it's not clear that this answer is successful - indeed, Anthony Newman (2005) has convincingly argued that it isn't.

Searle's account is not suitable for a theory that claims phenomenal sameness for internal duplicates and wants to account for all intentionality of conscious thoughts in terms of narrow phenomenal intentionality. But two-dimensional semantics - the other possibility mentioned by Kriegel - is not suitable for these purposes either. After all, the point of two-dimensional semantics is that certain thoughts have two different contents, a narrow and the wide one, so clearly, not all content is narrow. In fact, Horgan and Tienson say of their moderate externalism "Our distinction between narrow and wide truth conditions has some kinship to the approach of so-called twodimensional modal semantics" (Horgan and Tienson 2002, footnote 26).

3.

One potential problem for the approach Horgan et al. promote, as well as for two-dimensional semantics, is what we may call 'the problem of the inexpressibility of narrow content'. 'THorgan, Tienson and Graham tell us that

... insofar as $[\ldots]$ narrow truth-conditions are formulable linguistically $[\ldots]$, the formulation will employ only these kinds of vocabulary: (i) logical expressions, (ii) predicative expressions designating properties and relations to which the experiencer can mentally refer non-externalistically, and (iii) certain first-person indexical expressions. (Horgan et al. 2004, 312) 
I assume - and assume that Horgan et al. assume - that a thought we would express by using a name is not completely equivalent to any thought expressible with the above resources. This means, however, that the narrow content of a thought we would express by using a name is not formulable linguistically. The narrow truth-conditions of such thoughts can be expressed only approximately. A similar suggestion is adopted by some defenders of two-dimensional semantics, they say, for example, that the narrow content of 'water is wet' is something like, though not quite precisely, 'the watery stuff in my environment is wet'.

Horgan et al. acknowledge that the narrow truth-conditions cannot always be given “compact, cognitively surveyable, formulations" (Horgan et al. 2004, 313), but they don't think this is a decisive problem for their theory. Perhaps they are right. Nonetheless, it seems to me that it's worth asking whether this consequence could be avoided; and in what follows, I shall argue that it can. ${ }^{6}$

4.

This is how Horgan and Tienson explain why and how certain thoughts have externalist intentionality:

Consider, for example, thoughts about individuals. You [and] your Twin Earth doppelganger $[\ldots]$ have certain phenomenologically identical thoughts that you each take to be about a person named 'Bill Clinton'. [...] Your own thoughts are about the actual Bill Clinton. Your Twin Earth doppelganger's thoughts are about a different person on Twin Earth. You and your Twin Earth doppelganger have thoughts about different individuals, of course, because what a person's thoughts are about - or refer to - depends not only on phenomenal intentional content, but also on certain relations between the thinker and the thing the thought is about.

Straightforwardly, your thoughts about Bill Clinton are made true or false by facts about Bill Clinton, and your Twin Earth doppelganger's phenomenologically identical thoughts are made true or false by facts about the person who satisfies your duplicate's corresponding presupposition. [...]

The differing truth conditions just mentioned are wide truth conditions. (Horgan and Tienson 2002, 529) 
Let us compare this example to another example involving phenomenal duplicates. Suppose that I think:

(1) The inventor of bifocals was a man.

This thought is about the inventor of bifocals, and since Benjamin Franklin invented bifocals, the thought is about Benjamin Franklin. Straightforwardly, the thought expressed by (1) is made true or false by facts about Benjamin Franklin - as it happens, it is true, since Benjamin Franklin was indeed a man. Now consider a phenomenal duplicate of mine in a counterfactual situation where it's not Benjamin Franklin, but his wife, Deborah Franklin, who invents bifocals. When my Doppelgänger thinks (1), her thought is about Deborah Franklin - since she is thinking about the inventor of bifocals, and that's Deborah Franklin, as things happened in her history.

Straightforwardly, her thought is made true or false by facts about Deborah Franklin - as it happens, it is false, since Deborah Franklin was a woman.

There are two things I would like to note about this example. Horgan and Tienson say in the quote above that "what a person's thoughts are about - or refer to - depends not only on phenomenal intentional content, but also on certain relations between the thinker and the thing the thought is about". The 'inventor of bifocals' example illustrates the general truth of this statement. For example, in case of any thought that involves a contingently applicable description, what the thought is about will depend partly on how things are outside the thinker of the thought. The phenomenal intentionality of the thought that the inventor of bifocals was a man is never sufficient, in itself, to determine whom this thought is about - we also need the state of the world, or as we might say, the circumstances of evaluation, to settle this question.

The second remark is that as a consequence, we can locate a variance in truth-conditions in a surprisingly large range of cases. According to Horgan et al., my Clinton-thoughts have different truth-conditions from the truth-conditions of my Doppelgänger's phenomenally identical thoughts. As far as I can see, this is because the truth or falsity of our respective thoughts depend on facts concerning different individuals. However, the same could be said about my 'inventor of bifocals' thought and the phenomenologically identical thought of my Doppelgänger in the world where Deborah Franklin invents bifocals. The conditions for the truth of my thoughts are to be found in facts about Benjamin Franklin, the conditions for the truth of her thoughts is to be found in facts about Deborah Franklin. And these conditions are different. 
Should we then say that a thought like (1) has, apart from phenomenal intentionality, also externalistic intentionality, and corresponding wide content? This would be unusual, since even the majority of externalists would acknowledge that the content of descriptive thoughts like (1) remains the same throughout worlds where the description applies to different people (or where it applies to no-one). What varies from world to world is whom the thought is actually about, or whose gender decides whether the thought is true or false; but these circumstances are external to the content of the thought.

Perhaps some would question whether the thought that (1) is about Benjamin Franklin, by claiming that it is not about him, but about some properties. Sometimes defenders of this claim seek support in Russell's theory of descriptions, and its alleged consequence that definite descriptions are not referring expressions. I find this unhelpful. A theory of description would at least recognise that Franklin is the 'denotation' of the description, and this seems to me enough to convey the idea that in asserting (1), we say something about Franklin, or that the object of the thought expressed by (1) is Franklin. As Frank Jackson noted:

Nothing in Russell's theory goes against the fact that the words 'the tallest person alive in 1990' are quite distinct from the person who is the tallest person alive in 1990, and that there is some important relation between the words and the person which warrants a name. It is this relation that the description theorist calls 'reference'. (Jackson 1998, 207)

It is not my plan to defend the description theory of names. The point I want to borrow is only that there is an important relation between the words and the person, which we may call reference, or aboutness. This simple idea, without further heavy theoretical baggage, is enough for my argument to go through.

5.

We saw in the previous section that at least in some cases, the reference of our thoughts is determined partly by the content of the thought, and partly by factors external to this content. The actual object (Benjamin Franklin) of the thought expressed by 'the inventor of bifocals is a man' is determined partly by the (narrow, phenomenal) content of the thought and partly by the actual history external to this content, that is, by facts concerning the invention of bifocals. This means that there could be two circumstances - this world and another - where the content of the thought 
expressed by this sentence is the same, though the objects of the thoughts are different, because of a difference external to the content of these thoughts.

With this in mind, let us have another look at the Clinton example. My suggestion is that we treat it in a similar way. I say that the content of the thought I would express as 'Bill Clinton is a man' is determined entirely by phenomenology. The actual object of this thought (Clinton) is determined partly by this (phenomenal, narrow) content, and partly by factors external to this content; in this case, these facts probably have to do with a causal chain leading from an event of naming Clinton to my use of the name. The actual object of the thought is a product of two factors both in the Franklin case and the Clinton case: the narrow phenomenal content on the one hand, and the external circumstances on the other. And just like in the Franklin case, in the Clinton case too, the content is the same for me and my phenomenal Doppelgänger; and the difference in the objects of our thoughts is due to facts external not only to us, but also to the content of our thoughts.

In the case of the thought expressed by 'the inventor of bifocals was a man', there was no need to distinguish between two kinds of truth-conditions and content; there was only one content, and it was narrow and determined by phenomenology. Analogously, I suggest that for our Clinton thoughts, the only content these thoughts have is a phenomenally determined narrow content; and it is precisely this thought which is fully expressed by the sentence 'Bill Clinton is a man'. Hence we do not face the problem of the inexpressibility of narrow content. This is one important advantage of my purely internalist approach over the dual-content approach pursued by Horgan et al.

Consider the other example with a supposed need for externalistic intentionality: my thoughts about my mother, and those of my Doppelgänger about hers. Those of us who believe in phenomenal intentionality accept that the thoughts expressed by my own and my Doppelgänger's utterance of

(2) My mother loves orchids

share a narrow phenomenal content. This content is not sufficient to determine the actual object and the truth-value of these two thought-episodes. We also need the context of the utterances, by which I mean simply the features of an utterance or thought-episode which can influence its semantic value and the semantic value of its constituents. For example, the thinker, the time and the place of 
a thought-episode are constituents of the context, as well as the state of the world. 7 On this understanding, the context includes the circumstances of evaluation - the state of the world with respect to which we evaluate the truth of what is stated. Most people would agree that these features, the circumstances, are external to the content; if we compare a world where my mother loves orchids with another where she doesn't, the content expressed by (2) is the same. (This point is similar to the one made about (1) and the inventor of bifocals.) The proposal is that we treat all other features of the context as also external to the content. The relevant feature of the context of my thinking (2), and the other context where my Doppelgänger thinks (2), are needed to determine the actual object of the thought. But I suggest that we regard this case as two thoughts having the same content and different object, because of some difference external to the content of the thought - just as we did in the case of the inventor of bifocals. If we can do this, then we have a single narrow phenomenal content which is fully expressed by each use of (2).

These suggestions are likely to raise some objections, and in answering these objections, I hope I can offer a clearer view of the theory.

First, it may be objected that we cannot treat the cross-world and the cross-context cases analogously in the way I suggested, because contents have to be something like propositions, and propositions have their truth-value absolutely within a world. In contrast, my suggestion is that the content of (2) is something that changes its truth-value from context to context, within the same world. I shall begin to explain why this isn't a problem in Section 6.

Second, it may be objected that the suggested analogy between the Franklin case and the Clinton case obliterates the important and well-established semantic differences between definite descriptions and proper names, and between descriptive and singular thoughts. In fact, it doesn't. My proposal is compatible, for example, with a theory which holds that names are not synonymous with definite descriptions, and the reference of names is determined by a causal chain leading from an original baptism to the present use of the name. Of course, the theory isn't exactly the same as, say, the Kripkean theory of names, since it doesn't have the externalist consequences the Kripkean theory is usually supposed to have. Nonetheless, I believe it can accommodate the most important insights about the differences between names and descriptions, and between the thoughts we express with their help; or so I shall argue in section 7.

1 In this use of the term 'context' I follow John MacFarlane's usage; see below in Section 6. 
Third, continuing the first objection, it may be said that the only kind of content that I recognise (narrow, phenomenal, shared by Doppelgängers) is not properly referential and truthconditional, since it doesn't determine a unique reference and unique truth-conditions. For proper reference and truth-conditions, we need another kind of content, the objection continues. I shall show why this worry is unfounded in section 8 . Finally, I'll try to say a few words about the significance of this whole question in section 9.

6.

I said that we have a case of the same thought (with the same content) being about different objects, both in the example about the inventor of the bifocals, and in the example about my mother. But it may be objected that the cross-world and cross-context cases are not analogous. Contents have to be something like propositions traditionally conceived, whose truth-value of course varies from world to world, but not from context to context.

If contents are propositions traditionally conceived, then my proposal is flawed. However, in recent years there has been growing awareness that it is not compulsory to think about contents in this way. This idea has been developed, for example, by Peter Lasersohn and John MacFarlane (see Lasersohn 2005, MacFarlane 2005 and forthcoming). Indeed, the position I am suggesting here is similar to what MacFarlane calls 'non-indexical contextualism'.

Propositions are evaluated for truth and falsity with respect to certain circumstances of evaluation, and on the traditional conception of propositions, the circumstances of evaluation include only a possible world. In addition, some authors (e.g. Kaplan 1989, 502 ff) have argued that times have to be included in the circumstances of evaluation as well. So it is possible that the same proposition is expressed at different times, and has different truth-values because it is evaluated with respect to different times.

As MacFarlane points out, there is no prima facie theoretical obstacle to including further factors among the circumstances of evaluation: for example, standards of precision, or a 'counts-as' parameter (which determines what counts, say, as tall in a certain context). On such a theory, the very same content could be expressed in different contexts, and receive different truth-values, if evaluated with respect to different standards of precision, or different parameters of 'counts-as'.

A terminological note: Kaplan originally contrasted features of the context and circumstances of evaluation: the former influence the content of an utterance, the latter don't. In MacFarlane's usage, 'context' includes all the factors that, in addition to what is invariant in all 
utterances of the same sentence, determine truth-values. These include circumstances of evaluation. However, in agreement with Kaplan, he regards circumstances of evaluation as those features of the context which do not influence content. Suppose that there are different contexts of who counts as tall - say Holland and Hungary. Someone who holds that 'Chiara is tall' expresses different content in these contexts, would be an indexicalist about 'tall'. However, there is another option: that 'Chiara is tall' expresses the same content in these two contexts, but it is to be evaluated with respect to different circumstances of evaluation, which include a 'count-as' parameter. The claim that Chiara is tall is true when evaluated with respect to what counts as tall in Hungary, but false when evaluated with respect to what counts as tall in Holland. This would amount to non-indexical contextualism about 'tall' (MacFarlane, forthcoming).

You can see how my proposal is similar to this idea. I would like to say that my Doppelgänger and I express the same (narrow, phenomenally determined) content by 'Bill Clinton is a man'. - $\square$ order to determine the actual referent and the truth-value of an utterance of this sentence, the circumstances of evaluation have to include (say) the causal chain which leads to one's use of the name. Evaluated with respect to the chain that lead to my use, the thought is about Clinton; evaluated with respect to the chain that leads to my Doppelgänger's use, it's about TwinClinton. The hope is that all putative cases of externalistic intentionality can be handled as some similar form of context-dependence - that is, as cases where the same content is evaluated with respect to different circumstances of evaluation. $\square$ Further details are in the next section.)

7.

I suggested a certain analogy between the 'inventor of bifocals' case and the 'Clinton' case, and this may create the impression that I want to treat names as descriptions, or in other words, that I am proposing a descriptive theory of names. In fact, I am not. My suggestion is perfectly compatible with denying that names are synonymous with descriptions, with seeing essential differences between the semantics of names and descriptions and between the thoughts we express by names and descriptions.

Suppose, for example, that the reference of a name is at least partly determined by a mechanism that goes roughly along the following Kripkean lines. There is an event (or some class of events) which is responsible for someone or something acquiring a name. There is a causal chain leading from this event to the subsequent occasions where the name is used; speakers use the name to refer to the individual in question because he or she or it received this name in some appropriate 
way. The reference of definite descriptions, in contrast, is determined through satisfaction: it is the object which satisfies the description. In case of a pure description, the state of the world determines which object, if any, satisfies the description. In many cases, we may need a further contextual element to yield a unique reference; on this I'll say a bit more below. No naming event or causal chain plays a role in determining the reference of a description, unless, of course, the description explicitly mentions causal chains and the like, or it includes a name. Furthermore, names are rigid designators, for their reference is determined by the causal chain that links the speaker to her actual environment. In contrast, descriptions - unless they explicitly mention the actual world - function as non-rigid designators.

I do not want to decide now whether the theory just sketched is right; I would simply like to argue that it is compatible with my suggestion - and so my proposal doesn't obliterate possible deep differences between the functioning of names and descriptions, and between the thoughts we express with their help. The key point is this: whether the reference of an expression should be determined by the name-mechanism or by the description-mechanism depends on the phenomenal features of the thought we express by using these expressions.?

The arguments that show that names are not descriptions also support the claim that there is a phenomenal difference between descriptive thoughts and the thoughts we express by using proper names. Consider the situation of Kripke's brain-in-vat Doppelgänger, who speculates about the semantics of names and descriptions. His thoughts are phenomenally the same as Kripke's relevant thoughts, so the Doppelgänger takes himself to establish a difference between the functioning of names and descriptions, concludes that the former are rigid designators and the latter aren't, and so on. A brain-in-vat cannot base his conclusions on actual facts about his linguistic community, since he may be largely wrong about those; instead, he must base his conclusions on how things seem to him in his linguistic community. On the view defended by Horgan, Tienson and Graham (2004), brains in vats have only phenomenal intentionality, no extrinsic intentionality. The resources that a brain in a vat has at his disposal to establish his theory of reference must be all included in phenomenology, or how things seem to him - simply because he has nothing else to rely on. But surely Kripke's brain-in-vat Doppelgänger can come to the same conclusions as Kripke, conclusions which - assuming that he is right - would be true of the embodied Kripke's linguistic community. This means that the differences we can detect in our use of names and descriptions must be recoverable from the first-person, phenomenal viewpoint. 
It may be objected that on certain externalist views, a brain in a vat couldn't formulate thoughts that would be made true by the world of its embodied counterpart, because the truth- and reference-conditions of the brains-in-vats language are fundamentally different from those of ours. Some externalists would even deny that brains in vats have any mentality which is recognisably similar to our own. If this were so, then we could hardly credit Kripke's brain-in-vat Doppelgänger with coming up with a theory that we could so much as understand. In response to this, I would like to remind the reader that I am preaching here to the half-converted. For the purposes of this paper, I take it for granted that an embodied person and his brain-in-vat Doppelgänger share narrow contents possessing phenomenal intentionality. What I would like to show is that once this kind of intentionality is recognised, there is no need to recognise another kind.

If we reflect on what it's like to use names and descriptions, it is actually plausible that there is a phenomenal difference between the two kinds of cases - that is, as plausible as any claim, based on philosophical reflection, that there is some difference affecting their semantics. Consider what it would be like to use 'The Holy Roman Empire' as a name, and then as a description. What one intends to express by these two uses, it seems to me, feels different phenomenologically, according to the broad notion of phenomenology canvassed above. Similarly, it doesn't seem plausible that whereas I intend to, and do, use 'Clinton' as a name, there could be a Doppelgänger with a phenomenologically identical thought, who uses the term as a description.

It is precisely this phenomenal difference which points to the different semantic machineries that eventually result in actual references and truth-values. If an expression has the 'name-phenomenology', its reference is determined by a causal chain. If an expression has the 'description-phenomenology', its reference is determined by satisfaction. In the case of non-empty names, the present suggestion and the causal theory of names predict the same reference. If a brain in a vat thinks a thought with a name-phenomenology, it's the same thought as his embodied counterpart is thinking - only in the case of the brain in the vat there is no appropriate causal chain, or there is no appropriate individual involved in a name-acquiring practice. Hence the name lacks a reference, which is just what we should expect. That the name-phenomenology can be present without the name actually having a reference is clear from examples like 'Vulcan'.

Consider now the other example, my thoughts about my mother and my Doppelgänger's thoughts about hers. The reference of a contingent definite description like 'the inventor of bifocals' is determined by two factors: one is a phenomenally determined narrow content, the same in different uses (even in different worlds); the other is how things actually stand, or the possible 
world where the expression is used. For an expression like 'my mother', these two factors are not sufficient: if we take the constant content of an utterance and the state of the world, these two do not yield a reference - we also need a further feature of the context, the user of the expression.

This difference between the semantics of pure descriptions and context-sensitive expressions like 'my mother' is again perfectly compatible with my proposal. The crucial point is that the fact of context-sensitivity manifests itself in the consciousness of the user of the expression. Again, I find it hard to conceive a phenomenal duplicate who means by 'my mother' what I would express say as 'his mother' or 'the mother'. My thoughts about my mother have their specific 'indexical-phenomenology'. Then we might say that this phenomenal feature determines which external factors - external, that is, to the content of the thought - are needed to determine the actual referent of the term. The 'instructions', fixed by phenomenology, are the same in every context, but of course the actual object they point to may be different in different contexts.

The objection was that my proposal ignores the well-established differences between names and descriptions, which requires externalistic intentionality for thoughts expressed by names. My general strategy in answering this objection is first to ask for the objector's favorite theory of how the reference of a name is determined - the example I considered was the theory of causal chains. Then I agree to adopt the mechanism with the proviso that every factor relevant to the determination of reference - states of the world, causal chains, features of context - that is not shared by phenomenal Doppelgängers is deemed external to the content of the thought. Finally, I contend that thoughts that require different mechanisms for determining their reference will exhibit a matching phenomenal difference. This is supported by the observation that such differences are recoverable by philosophical reflection, from the first-person phenomenal view of a brain in a vat. A note: I'm not suggesting that the mechanism is explicitly represented in the phenomenal content of the expression - for example, that the content of Clinton-thoughts could be translated as "the man who started the causal chain that led to this use of 'Clinton' is so-and-so". To repeat, I am not committed to a descriptive theory of names. The nature of the mechanism is revealed by philosophical reflection on the phenomenology of certain thoughts - such reflection often enough gives an analysis without giving a synonym.

The theory we get as a result is compatible with my suggestion that the only kind of content is phenomenally determined narrow content, but its results match closely the results of the theory put forward by the objector. Where the objector's theory predicts no reference, so does mine. Where the objector's theory predicts the reference is Clinton, rather than Twin-Clinton, mine 
predicts the same. Phenomena like rigid designation can be accounted for by my theory just as well as by the objector's theory. 2 In summary, I can accommodate any theory of reference the objector likes. The only difference between us is that the objector takes reference to be internal to content, whereas I take it to be external to content. This may, of course, be the basis for a separate objection against my account. I address this other objection in the next section.

8.

Let us now turn to the third objection we formulated earlier: that narrow phenomenal content is not properly referential and truth-conditional. This objection is often thought to be fatal for an uncompromisingly internalist conception of mental content. Putnam's original argument for broad content (Putnam 1975) was also based on the claim that an internalist conception is incompatible with the principle that meaning determines reference.

Here is a sketch of the argument that phenomenal content is not referential.

1. That content is referential means that content determines reference.

2. If referential content determines reference, then difference in reference implies difference in referential content.

3. My Twin Earth Doppelgänger and I refer to different individuals with our phenomenally identical Clinton-thoughts.

4. Our referential contents then must be different, but our phenomenal contents are the same.

5. Therefore, phenomenal content is not referential content.

This argument works only if the first premise is understood in a specific way, so as to license the second step. When we say that content determines reference, we must mean that content alone determines reference. For if content alone doesn't determine reference, but instead content plus something else determines reference, then difference of reference doesn't imply difference in content, since difference in reference could be due to difference in the 'something else'.

Is it generally true that content alone must determine reference for it to count as referential content? There is very good reason to think that it is not. Consider the earlier example about the inventor of bifocals. The actual object of the thought is not determined by the content of the expression alone; we also need an additional factor, namely, the state of the world. And when we find that different uses - in different worlds - result in different reference, we do not infer from this 
a difference in content. Instead, we hold that the content is the same, and the difference in reference is due to factors external to this content. As I said in Section 4, descriptions serve just as well for talking about things, or referring to things, as names do. So descriptive content is referential content, but doesn't in itself determine reference. This means that it cannot be a general truth about content that, in order to be referential, it must alone determine reference. It's instructive to recall what Putnam says when he introduces the idea that intension determines extension: “ ... it was taken to be obvious that [...] two terms cannot differ in extension and have the same intension. Interestingly, no argument for this impossibility was ever offered." (Putnam 1975, 218) Putnam himself doesn't do anything to improve this state of affairs, but if I am right, this isn't very surprising. The example of the 'inventor of bifocals' shows that there is no such impossibility: two terms can differ in extension and have the same intension. Yet the expression 'the inventor of bifocals' refers, and thus can certainly be rated as referential in one important sense. So at least in one important sense, content can be referential without determining reference all on its own.

Given that it is not generally true that content alone determines reference, the above argument against the referentiality of narrow content is not conclusive. $\left.\right|^{3}$ For even though the reference of my Clinton-thought is different from that of my Doppelgänger's Clinton thought, this would entail a difference in content only if these contents alone determined their reference. However, my suggestion is precisely that they don't. Of course, there are particular theories which entail that the contents of thoughts we express by using names essentially involve their object, and hence are sufficient in themselves to determine reference. But the aim of this paper is to argue that these theories are mistaken, because all content is narrow and phenomenal. $\square$ Given that most of us would agree that there are bona fide truth-conditional contents which do not involve any external object essentially - namely descriptive contents - there doesn't seem to be anything in the very notion of content that would forbid the claim that all contents are like that.

These considerations hopefully establish that the proposal of this paper is not threatened by certain objections. This, however, still doesn't amount to a positive argument. I say that we can treat Clinton-thoughts as having a constant content, and having their object determined by this content plus some external factors. But why should we? A complete answer to this question would require much more than I can supply in the remaining space. All I can do in the next section is to indicate the outlines of a possible response.

9. 
It is clear that the objects of our thoughts - what those thoughts are about - are in some sense relevant to the nature of our mental states. Thus thinking about water and thinking about wine are different mental states - because the objects of these thoughts differ. But it seems equally clear to me that in certain third-person mental state attributions, there is a way of talking about the objects of someone's thoughts which does not shed light on those thoughts' nature. Oedipus, during his marriage to Jocasta, no doubt entertained many thoughts about her - and since Jocasta happened to be his mother, the object of these thoughts was his mother. Consequently, the truth-value of these thoughts depended on how things were with his mother. Yet I would insist that it would be misleading to characterize the nature of these thoughts with reference to his mother - whatever the content of these thoughts were, they did not include the conceptual component 'mother'.

Often when we describe what someone thought or said we make use of information which is available to us, but not necessarily available to the subject. This is a perfectly legitimate procedure, but may involve elements which are not relevant to the nature of the subjects' thoughts qua thoughts. Hence I do not want to deny that we could, when reporting what someone said or thought, classify thoughts or utterances in a way different from what I am suggesting. But I'd like to insist that this does not adequately reflect those thoughts' real, intrinsic nature.

What sort of considerations could decide the 'real' nature of thoughts? I believe these would have to do with self-knowledge, for example, or with the characteristic role of thoughts in the mental life of rational and autonomous agents. I already mentioned another consideration: other things being equal, we should prefer a theory which makes it possible to express the phenomenally determined narrow content of all of our thoughts, given the important role these contents play in our mental lives. But the view that combines phenomenal intentionality with externalistic intentionality makes these contents potentially inexpressible with our linguistic resources.

A lot more could and should be said about this of course, but I would like to consider the position of someone who became convinced, for example on the basis of arguments about selfknowledge and rationality, that the nature of the mental requires an uncompromisingly internalist treatment of contents; that nothing that pertains to the nature of our mind could lie outside the essentially first-person perspective. What I wanted to show in this paper is that there are no obstacles to holding such a position; for if what I said here is right, then we have a form of narrow intentionality, which is based entirely on phenomenology, provides respectable truth- and referenceconditions, requires no other form of intentionality, and is fully expressible by the linguistic resources we have. What more should one hope for in a theory of phenomenal intentionality? ${ }^{16}$ 


\section{References}

Farkas, Katalin 2006a "Indiscriminability and the sameness of appearance," Proceedings of the Aristotelian Society, CVI/II, 205-25.

Farkas Katalin 2006b "Semantic Internalism and Externalism," in Ernest Lepore and Barry C. Smith (eds.) Oxford Handbook of the Philosophy of Language, Oxford: Oxford University Press, 323-40.

Fodor, Jerry A. 1987 Psychosemantics, Cambridge, Mass.: MIT Press.

Horgan, Terence and John Tienson 2002 "The Intentionality of Phenomenology and the Phenomenology of Intentionality," in David Chalmers (ed.) Philosophy of Mind: Classical and Contemporary Readings, Oxford: Oxford University Press, 520-31.

Horgan, Terence, John Tienson and George Graham 2004 "Phenomenal Intentionality and the Brain in a Vat," in Richard Schantz (ed.) The Externalist Challenge: New Studies on Cognition and Intentionality, Berlin: Walter de Gruyter, 297-317.

Jackson, Frank 1998 "Reference and Description Revisited," Philosophical Perspectives, 12, 20118.

Kaplan, David 1989 Demonstratives, in Joseph Almog, John Perry, Howard Wettstein (eds.) Themes from Kaplan, Oxford: Oxford University Press, 481-563.

Kriegel, Uriah forthcoming "Intentional Inexistence and Phenomenal Intentionality," Philosophical Perspectives 22 (2008) http://uriahkriegel.com/downloads/viability.pdf

Lasersohn, Peter 2005 “Context dependence, disagreement, and predicates of personal taste," Linguistics and Philosophy, 28, 643-86.

Loar, Brian 2003 "Phenomenal Intentionality as the Basis of Mental Content," in Martin Hahn , Bjørn Ramberg (eds.) Reflections and Replies: Essays on the Philosophy of Tyler Burge, Cambridge, MA: MIT Press, 229-58

MacFarlane, John 2005 "Making Sense of Relative Truth," Proceedings of the Aristotelian Society $105,321-39$

MacFarlane, John forthcoming, "Semantic Minimalism and Nonindexical Contextualism," in Gerhard Preyer and Georg Peter (eds.) Context-Sensitivity and Semantic Minimalism: Essays on Semantics and Pragmatics, http://sophos.berkeley.edu/macfarlane/semanticminimalism.pdf 


\title{
Newman, Anthony 2005 “Two Grades of Internalism (Pass and Fail),” Philosophical Studies,
} 122/2, 153-69.

\author{
Putnam, Hilary 1975 "The Meaning of 'Meaning"” in Mind, Language and Reality, Cambridge: \\ Cambridge University Press, 215-71.
}

Searle, John R. 1983 Intentionality, Cambridge: Cambridge University Press.

\footnotetext{
${ }^{1}$ I argue for this in Farkas 2006a.

${ }^{2}$ The nature of wide contents, and the relation between phenomenal and externalist intentionality, are conceived differently by Loar on the one hand, and Graham, Horgan and Tienson on the other. Here I just want to point out that they all accept some form of content externalism.

${ }^{3}$ However, we cannot claim that all intentionality is phenomenal, if unconscious thoughts have intentionality. The hope is that the intentionality of unconscious thoughts is derivative from phenomenal intentionality (Loar 2003).

${ }^{4}$ If I'm thinking about my Twin's mother and she is thinking about mine, the same can be said of course. Here the relevant relation a particular bears to oneself is being 'the mother of one's Doppelgänger'.

${ }^{5}$ Fodor (1987) also argues that narrow content is inexpressible, but he doesn't regard it as a decisive objection against a dual-content view.

${ }^{6}$ The question of the expressibility of narrow content actually involves different issues; one point mentioned by Horgan et al. is that often no description can properly convey the rich content of perception. This seems to me a different question from the question of whether the narrow content of a sentence including a name can be expressed linguistically.

${ }^{7}$ I cite Lasersohn's and MacFarlane's work to support the very idea of a full-blown content that can vary in truth-value within the same world; that is, to support the intelligibility of the 'non-indexical contextualist' position. It is a further question which expressions should be treated in this manner, and here I don't want to claim support from Lasersohn or MacFarlane.

${ }^{8}$ So if Kriegel's suggestion that we treat problematic cases as 'indexical' is the same as treating them as 'contextdependent' in the broad sense of 'context' which may include circumstances of evaluation, then I am in agreement. We should keep in mind the terminological differences, since 'indexicality' means something else in MacFarlane's usage.

9 This claim relies on the broad understanding of the 'phenomenal' suggested by the aforementioned defenders of phenomenal intentionality. This broad understanding goes beyond the sensory or the feeling-related aspects phenomenology. For example, Horgan and Tienson (2002) argue that there is something it is like to entertain a certain intentional content, or to have a certain propositional attitude towards a content. Conscious thoughts, even if they don't involve sensory or emotional elements, have a distinct phenomenology that attaches to their content and attitude features.

${ }^{10}$ Two of the anonymous referees mentioned that my suggestion doesn't account for the crucial distinction between singular thoughts and descriptive thoughts, or if it does, it's not clear how. My response is that I can recognise a difference between name-phenomenology and description-phenomenology. Of course this distinction is not quite the same as that between singular and descriptive thought, as it is usually conceived, but I believe it accounts for everything important.

${ }^{11}$ This is similar to the role played by "grounding presuppositions" in Horgan et al. (2004).

${ }^{12}$ One of the referees objected that my argument leaves out one crucial distinction between descriptive thought and singular thought, namely, that the content of singular thoughts includes an individual. I wouldn't say I leave this out - I deny it. My thesis is that I could have a Clinton-thought even if I were a brain in a vat. If the worry here is that no such thought is sufficient to determine a reference, I address this problem in the next section.

${ }^{13}$ In Farkas 2006b I briefly indicate how similar considerations can be used to undermine the Twin Earth argument for externalism.

${ }^{14}$ Or at least derives from content that is narrow and phenomenal - see n. 3 above.

${ }^{15}$ I hope that these considerations help to address the worries raised by Loar (in Loar 2003) that narrow phenomenal content cannot be truth-conditional.

${ }^{16}$ I would like to thank Tim Crane for many discussions on this and related subjects, and three anonymous referees for valuable comments on a previous draft. I would also like to thank the support of the Hungarian OTKA (grant no.
} 
T046757). This paper was written while I was a visitor at the Center for Subjectivity Research at the University of Copenhagen. 